\title{
INCIDÊNCIA E CARACTERIZAÇÃO MORFOLÓGICA DE Alternaria alternata E Bipolaris bicolor EM SEMENTES DE TRIGO 'BRS 264’
}

Gustavo Henrique Silva Peixoto, Paulo Henrique Pereira Costa Muniz, Mariany Dalila Milan, Franciely Magalhães Barroso, Daniel Diego Costa Carvalho

Universidade Estadual de Goiás - UEG, Câmpus Ipameri, GO. E-mail: daniel.carvalho@ueg.br

\section{RESUMO}

As sementes são consideradas importantes veículos de disseminação de patógenos. O objetivo deste estudo foi quantificar a incidência de A. alternata e B. bicolor em sementes de trigo 'BRS 264' e realizar a caracterização morfológica destes fungos. Para tanto, quatro avaliações sanitárias foram realizadas, empregando-se caixas acrílicas transparentes gerbox. Com finalidade de inibir a germinação, as sementes foram incubadas em BOD a $25 \circ \mathrm{C}$ e regime de $12 \mathrm{~h}$ de luz durante 24 horas e, em seguida, transferidas para freezer a $-20 \circ \mathrm{C}$ e escuro por 24 horas. Posteriormente, as sementes foram incubadas em BOD a 25 ㄷ $\mathrm{C}$ 12 horas de luz por mais 8 dias, onde a incidência foi estimada diariamente. Em seguida foram preparadas lâminas semi-permanentes para posterior registro de imagens e a mensuração de estruturas dos fungos pela obtenção de 30 medidas de cada componente estrutural avaliada em microscópio de luz Leica DM500, com auxílio do programa LAS EZ 2.0 (100x). Os resultados referentes às estruturas fúngicas e de incidência foram submetidos à análise de variância e de regressão, respectivamente. A partir disso, foi possível confirmar através da caracterização morfológica a presença de $A$. alternata e $B$. bicolor, os quais apresentaram 41,5 e 16,5\% de incidência nas sementes aos 8 dias de avaliação, respectivamente.

Palavras-chave: patologia de sementes; taxonomia de fungos; Triticum aestivum.

\section{INCIDENCE AND MORPHOLOGICAL CHARACTERIZATION OF Alternaria alternata E Bipolaris bicolor IN WHEAT SEEDS 'BRS 264'}

\begin{abstract}
The seeds are considered important spread vehicles of pathogens. This study aimed to quantify the incidence of $A$. alternata and B. bicolor in wheat seeds 'BRS 264' and to perform morphological characterization of these fungi. Therefore, four sanitary evaluations were performed in gerbox transparent acrylic boxes. In order to inhibit germination, the seeds were incubated in a BOD at 25으 and 12-hour light period for 24 hours and, then, transferred to freezer at $-20 \circ \mathrm{C}$ and dark period for 24 hours. Just after, the seeds were incubated in BOD chamber at 25ㅇ and 12-hour light period during 8 days, which the incidence was estimated daily. Then, semi-permanent slide mountings were prepared for subsequent capturing images and measurement of fungi structures by obtaining 30 measurements of each structural component evaluated under a Leica DM500 light microscope, using the LAS EZ 2.0 (100x) software. The results concerning fungal structures and incidence were submitted to variance and regression analysis, respectively. From this, it was possible to confirm $A$. alternata and $B$. bicolor presence through morphological characterization, which presented 41.5 and $16.5 \%$ of incidence on the seeds at 8 days of evaluation, respectively.
\end{abstract}

Keywords: seeds pathology; fungi taxonomy; Triticum aestivum.

\section{INTRODUÇÃO}

No que se trata da disseminação de patógenos, as sementes são consideradas importantes veículos de alastramento principalmente devido a introdução da doença por longas distâncias (CORRÊA et al., 2008) e por permanecerem viáveis por um período longo, dando condições aos microrganismos que ali se encontram (TELLES NETO et al., 2007). A infecção ocorre na transmissão do patógeno da semente para a plântula estabelecendo uma relação com os órgãos ou partes do hospedeiro a qual garante a sobrevivência e posteriormente a sua difusão, através de um processo cíclico natural de duração 
indefinida (REIS, 1987; GARCIA JUNIOR et al., 2008). De acordo com Casa et al. (2012), os fungos necrotróficos são fontes relevantes de inóculo inicial e sobrevivem se mantendo viáveis mesmo em período de entressafra na forma de micélio no endosperma, no tegumento ou no embrião de sementes de cereais de inverno, como o trigo. Estes desenvolvem-se nos coleóptilos das sementes no período de cultivo, havendo possibilidade de desenvolverem-se também na plúmula das sementes e consequentemente infectar as folhas primárias.

Com vistas a se avaliar a qualidade sanitária de determinada amostra de sementes, é necessário que se faça a análise desta, através de diversos métodos, como o blotter test e em meio com presença de ágar, sendo que tais práticas são fundamentais para testificar as condições de um lote através da quantificação e qualificação dos patógenos presentes (CELANO et al., 2012; DANELLI et al., 2012). Neste contexto, realizar a correta caracterização dos patógenos ocorrentes nas sementes auxiliará em uma identificação precisa, evitando-se divergências na interpretação que podem ocorrer mediante avaliação fenotípica (LIMA et al., 2004; ANGELOTTI et al., 2006).

Diversas espécies de fungos podem causar a helmintosporiose ou mancha foliar no trigo, como Bipolaris sorokiniana, B. bicolor, B. sacchari e Helminthosporium spp., as quais podem reduzir o rendimento do cereal em até $80 \%$ e utilizam da semente como principal mecanismo de sobrevivência entre safras (MOREJON et al., 2006; SOLEIMANI; KAZEMI, 2006; KOBAYASTI; PIRES, 2011). Outro fungo encontrado em sementes de cereais é a Alternaria alternata, considerada uma espécie cosmopolita (CASA et al., 2012; XIAO et al., 2012), além desta podem ser encontradas também espécies como $A$. infectoria e $A$. triticina (PERELLÓ; SISTERNA, 2006; KHUDHAIR et al., 2014; ĐISALOV et al. 2015). As espécies de Alternaria são consideradas patógenos nãoespecíficos, dada a capacidade de infectar diversas plantas como cereais, oleaginosas, frutas, vegetais e até mesmo espécies ornamentais, causando danos não somente produtivos e econômicos mas também reduzindo a qualidade do produto final através da liberação de micotoxinas (KAHL et al., 2015).

As pesquisas a respeito da caracterização morfológica e incidência de fungos em sementes de trigo tem se mostrado insuficientes na região do sudeste goiano, portanto faz-se necessário o levantamento da incidência, isolamento e a correta caracterização morfológica uma vez que a cultura possui no país e seu potencial produtivo na região supracitada. Este trabalho teve objetivo estimar a incidência de $A$. alternata e $B$. bicolor em sementes de trigo 'BRS 264' e posterior caracterização morfológica destes fungos.

\section{MATERIAL E MÉTODOS}

\section{Análise sanitária das sementes infectadas e infestadas por patógenos}

O estudo foi conduzido no Laboratório de Fitopatologia da Universidade Estadual de Goiás

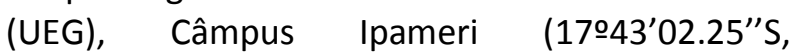
4808'36.63"'W, $794 \mathrm{~m}$ ), no ano de 2018. O experimento com análise sanitária foi conduzido em conformidade com o manual de análise sanitária de sementes (BRASIL, 2009), em que caixas gerbox $(11 \times 11 \times 3,5 \mathrm{~cm})$ foram submetidas à assepsia com álcool $70 \%$ e, em seguida, foram colocados dois papéis mata-borrão, previamente umedecidos com água destilada esterilizada a 2,5 vezes seu peso. Após isso, 25 sementes não tratadas de trigo 'BRS 264' foram semeadas em cada caixa gerbox. Em seguida, com finalidade de inibir a germinação, as sementes foram (1) incubadas em câmara do tipo BOD a $25 \% \mathrm{C}$ e regime de $12 \mathrm{~h}$ de luz durante 24 horas, (2) transferidas para freezer onde foram submetidas à temperatura de congelamento, cerca de $-20^{\circ} \mathrm{C}$ (TANAKA et al., 2008), e escuro por 24 horas e posteriormente, (3) as sementes foram novamente incubadas em BOD a $25^{\circ} \mathrm{C}$ e 12 horas de luz por mais 8 dias, iniciando a contagem no primeiro dia. Durante os nove dias a 25 으 e $12 \mathrm{~h}$ de luz, a incidência de $A$. alternata e $B$. bicolor nas sementes foi estimada diariamente com o auxílio de microscópio óptico.

\section{Caracterização morfológica dos patógenos encontrados \\ No decorrer do item anterior, a} identificação dos fungos foi realizada mediante confecção de lâminas semi-permanentes contendo o material biológico removido diretamente da semente infectada, e utilizando ácido lático como meio de montagem para as lâminas das estruturas fúngicas encontradas. Para caracterização morfológica dos fungos, foi realizado o registro de imagens e a mensuração de suas estruturas pela obtenção de 30 medidas de cada componente para cada lâmina (CARVALHO et al., 2014; VASCONCELOS et al., 2014) no microscópio de luz Leica DM500, com auxílio do programa LAS EZ 2.0 (100x). Os 
componentes mensurados foram comprimento e largura para os gêneros Bipolaris e Alternaria e comprimento do bico para Alternaria. As preparações microscópicas foram depositadas no Laminário Fitopatológico da UEG.

\section{Análise estatística}

Os resultados relativos às medidas das estruturas do fungo foram submetidos à análise de variância (ANAVA) para obtenção do coeficiente de variação destas e à análise de regressão para obtenção de modelos para a incidência dos fungos, com auxílio do programa SISVAR 5.3 (FERREIRA, 2011).

\section{RESULTADOS E DISCUSSÃO}

Para a Alternaria, os conídios obtidos a partir da semente apresentaram dimensões para comprimento e largura de, respectivamente, 20,2 $-32,7 \times 6,8-11,6 \mu \mathrm{m}(24,7 \times 9,1 \mu \mathrm{m})$ e bico de $3,7-7,1 \mu \mathrm{m}(5,2 \mu \mathrm{m})$ (Tabela 1). Os conídios de todos os materiais analisados apresentaram coloração marrom clara, com formato ovoide ou elipsoidal. (Figura 1A). As colônias apresentaram aspectos tipicamente relacionados à Alternaria alternata, com coloração acinzentada à marrom escura, com micélios com tonalidade verde oliva (Figura 1B). Os coeficientes de variação para comprimento, largura e bico dos conídios foram de, respectivamente, $11,85 \%, 13,04 \%$ e $18,94 \%$.

Quanto ao Bipolaris, foram obtidos conídios a partir da semente com dimensões de
$54,0-73,6 \times 13,0-16,2 \mu \mathrm{m}(61,8 \times 14,6 \mu \mathrm{m})$ para, respectivamente, comprimento e largura (Tabela 2). Os conídios apresentaram forma reta, semelhante à um porrete ou taco, raramente curvos, com bordas arredondadas, com coloração variando de marrom à marrom-escuro (Figura 2A). Em relação às colônias, estas possuem similaridade à um algodão e coloração acinzentada, com conídios dispersos pelo papel mata-borrão e micélio, sendo este abundantemente aéreo (Figura 2B).

Os coeficientes de variação encontrados para comprimento e largura corresponderam à, respectivamente, $8,43 \%$ e $6,37 \%$. Quanto a incidência, ao oitavo dia do teste de sanidade, $A$. alternata se mostrou presente em $41,5 \%$ das sementes, enquanto que para B. bicolor a incidência foi de $16,5 \%$. As leituras diárias de incidência permitiram estabelecer modelos quadráticos significativos e com altos coeficientes de determinação (Figura 3).

As medidas obtidas a partir dos conídios de Alternaria encontrados na superfície das sementes de trigo do presente estudo, indicaram a espécie tratar-se de $A$. alternata, uma vez que estas se encontraram em faixas de medidas já reportadas por outros autores: $18,0-50,0 \times 5,0-$ $18,0 \mu \mathrm{m}$ para comprimento e largura, respectivamente, e 2,0 - 20,0 $\mu \mathrm{m}$ para o bico (MISAGHI et al., 1978; CARVALHO et al., 2008; VASCONCELOS et al., 2014).

Tabela 1. Características morfológicas de conídios de Alternaria spp. em diferentes hospedeiros, incluindo a espécie encontrado em sementes de trigo 'BRS 264' (Ipameri, Goiás, 2018).

\begin{tabular}{|c|c|c|c|c|}
\hline \multirow{2}{*}{$\begin{array}{l}\text { Espécie de } \\
\text { Alternaria }\end{array}$} & \multirow{2}{*}{ Hospedeiro / órgão da planta } & \multicolumn{2}{|c|}{ Tamanho do conídio ( $\mu \mathrm{m})$} & \multirow{2}{*}{$\begin{array}{c}\text { Tamanho do } \\
\text { bico }(\mu \mathrm{m})\end{array}$} \\
\hline & & Comprimento & Largura & \\
\hline A. triticina $^{(1)}$ & T. aestivum / folha & $15,0-92,0$ & $8,0-35,0$ & $*$ \\
\hline A. triticina $^{(2)}$ & T. aestivum / semente & $18,0-88,0$ & $7,0-18,0$ & $*$ \\
\hline A. infectoria ${ }^{(3)}$ & T. aestivum / semente & $15,0-25,0$ & $4,5-7,0$ & $*$ \\
\hline A. triticimaculans ${ }^{(4)}$ & T. aestivum / folha & $41,2-97,5$ & $11,2-18,7$ & $*$ \\
\hline A. alternata $^{(5)}$ & Citrus / fruto & $22,5-35,0$ & $5,0-10,0$ & $2,5-7,5$ \\
\hline A. alternata ${ }^{(6)}$ & $\begin{array}{l}\text { Solanum tuberosum / } \\
\text { tubérculo }\end{array}$ & $19,7-45,4$ & $8,5-18,0$ & $2,6-11,9$ \\
\hline A. alternata ${ }^{(7)}$ & S. lycopersicum / caule & $18,0-50,0$ & $7,0-18,0$ & $2,0-20,0$ \\
\hline A. alternata $^{(8)}$ & T. aestivum / sementes & $20,2-32,7$ & $6,8-11,6$ & $3,7-7,1$ \\
\hline
\end{tabular}


Figura 1. A. alternata encontrada em sementes de trigo 'BRS 264'. (A) Conídios de formato elipsoidal ou ovoide, de coloração marrom clara e com septos longitudinais e transversais. 40x. (B) Colônia tipicamente acinzentada a marrom escura, com tonalidade verde oliva. Ipameri, Goiás, 2018.

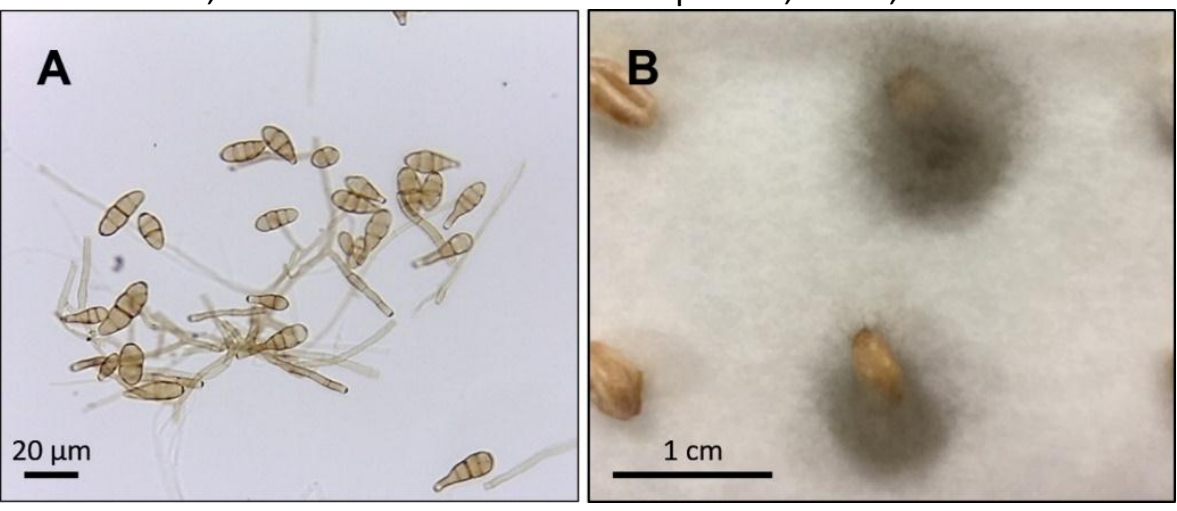

Tabela 2. Características morfológicas de conídios de Bipolaris spp. em diferentes hospedeiros, incluindo encontrado em sementes de trigo 'BRS 264' (Ipameri, Goiás, 2018).

\begin{tabular}{|c|c|c|c|}
\hline \multirow{2}{*}{ Espécie de Bipolaris } & \multirow{2}{*}{ Hospedeiro / órgão da planta } & \multicolumn{2}{|c|}{ Tamanho do conídio ( $\mu \mathrm{m})$} \\
\hline & & Comprimento & Largura \\
\hline B. sorokiniana ${ }^{(1)}$ & T. aestivum / semente & $68,0-99,0$ & $17,0-24,0$ \\
\hline B. spicifera ${ }^{(2)}$ & Sorghum bicolor / folha & $20,0-31,0$ & $7,5-12,5$ \\
\hline B. sorghicola ${ }^{(3)}$ & S. bicolor / folha & $72,5-75,0$ & $10,0-12,5$ \\
\hline B. bicolor ${ }^{(4)}$ & S. bicolor / semente & $49,6-65,7$ & $14,3-18,5$ \\
\hline B. bicolor ${ }^{(5)}$ & T. aestivum / semente & $40,0-78,0$ & $12,1-17,3$ \\
\hline B. bicolor ${ }^{(6)}$ & T. aestivum / semente & $54,0-73,6$ & $13,0-16,2$ \\
\hline
\end{tabular}

${ }^{(1)}$ Brasil (2009); ${ }^{(2)}$ Ünal et al. (2011); ${ }^{(3)}$ Silva et al. (2006); ${ }^{(4)}$ Carvalho et al. $(2014) ;{ }^{(5)}$ Morejon et al. $(2006) ;{ }^{(6)}$ Espécie encontrada em sementes de trigo 'BRS 264', Ipameri, Goiás, 2018.

Figura 2. B. bicolor encontrado em sementes de trigo 'BRS 264'. (A) Conídios de formato elipsoidal, reto, bordas arredondadas, de aspecto semelhante à um taco, raramente curvo, com coloração marrom à marrom escuro. 100x. (B) As setas mostram colônias com aspecto acinzentado, semelhante à um algodão, conídios dispersos pelo micélio, sendo este na maior parte aéreo. Ipameri, Goiás, 2018.

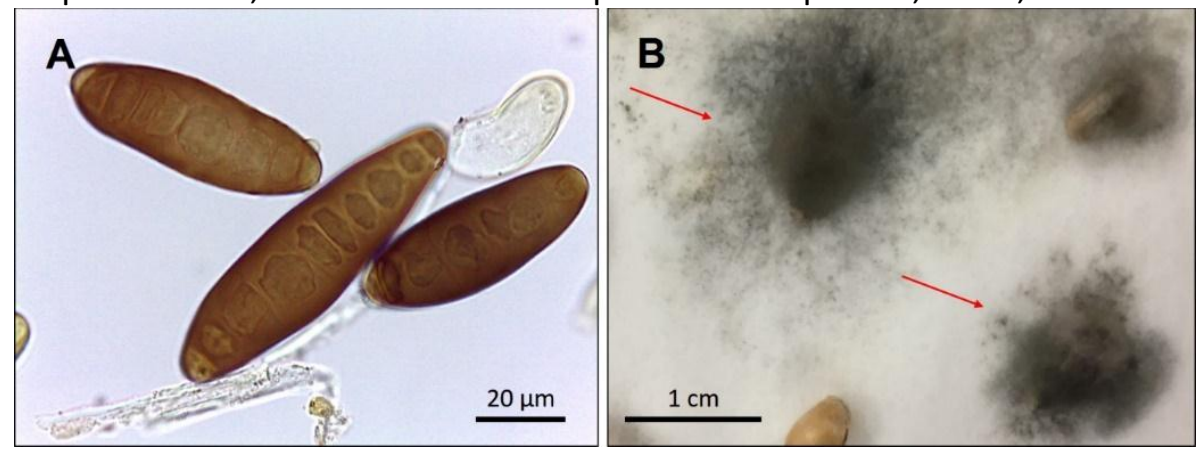

Figura 3. Incidência de Alternaria alternata e Bipolaris bicolor no decorrer de 8 dias em sementes de trigo 'BRS 264'. 


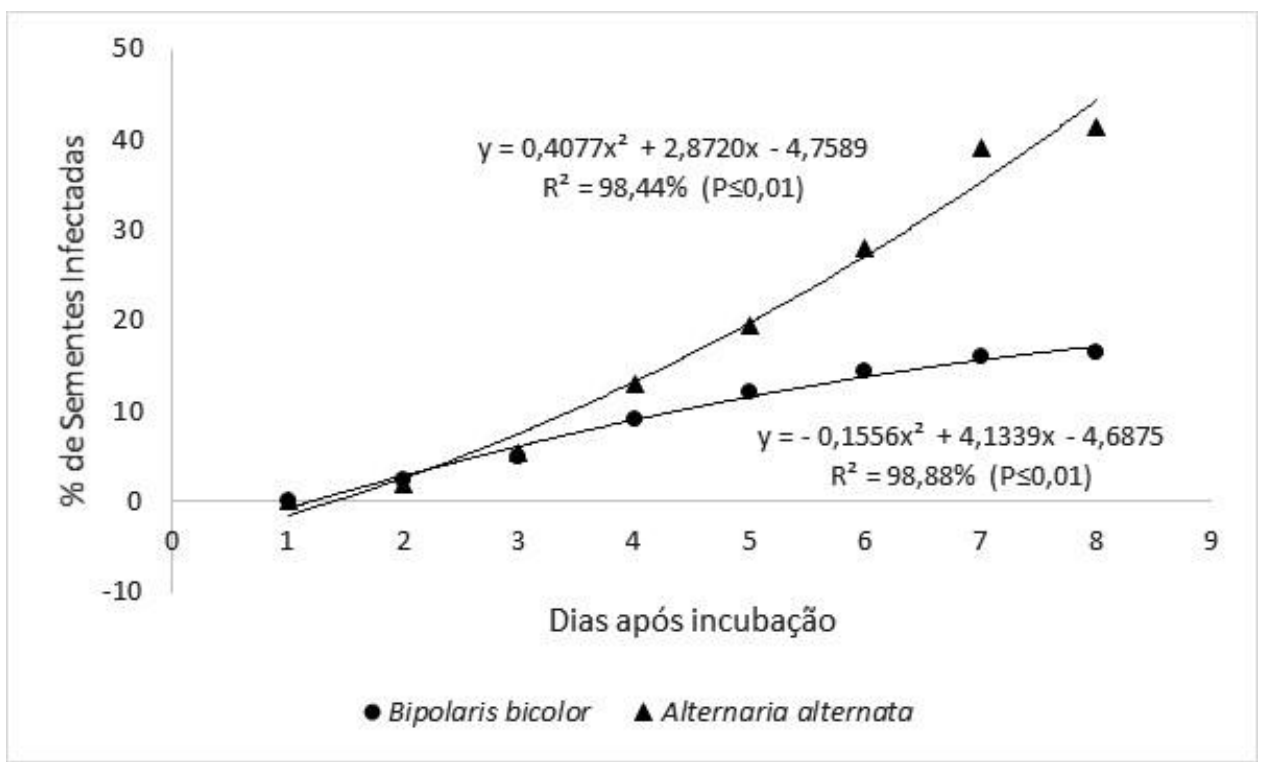

De forma oposta, apesar da possibilidade de se encontrar em sementes e folhas de trigo a espécie $A$. triticina, os resultados encontrados para conídios desta espécie $(15,0-92,0 \times 7,0-$ $35,0 \mu \mathrm{m})$ evidenciam dimensões muito maiores quando comparadas com as encontradas no presente trabalho (PERELLÓ; SISTERNA, 2006; KHUDHAIR et al., 2014). Quanto a A. infectoria, também considerada patogênica a sementes de trigos, esta pode ser descartada por possuir dimensões de conídios de 15,0 - 25,0 x 4,5 - 7,0 $\mu \mathrm{m}$, onde tanto para o comprimento quanto para largura as mensurações reportadas são inferiores (ĐISALOV et al., 2015).

Durante a análise estatística das dimensões dos conídios, a variabilidade das medidas de comprimento e largura $(11,85 \%$ e $13,04 \%$, respectivamente) corroboram com Vasconcelos et al. (2014), que verificaram valores de $23,29 \%$ e $17,82 \%$, respectivamente, fundamentando a ideia de que isso ocorre devido ao fato da obtenção de conídios ter sido feita diretamente do tecido vegetal (semente) sem repicagem para meio de cultura e posterior purificação, aumentando a chance de variações ambientais.

Dimensões de conídios de $B$. bicolor ocorrentes em sementes de trigo $(40,0-78,0 \mathrm{x}$ $12,1-17,3 \mu \mathrm{m})$ reportadas por Morejon et al. (2006) foram muito similares às dimensões encontradas para o fungo Bipolaris encontrado nas sementes 'BRS 264', bem como dimensões $(49,6-65,7 \times 14,3-18,5 \mu \mathrm{m})$ publicadas para $B$. bicolor ocorrentes em sementes de sorgo (CARVALHO et al., 2014). Outra espécie ocorrente em sementes de trigo é $B$. sorokiniana, no entanto, as dimensões reportadas $(68,0-99,0 \mathrm{x}$
17,0 - 24,0 $\mu \mathrm{m}$ ) pelo manual de análise sanitária de sementes (BRASIL, 2009), são muito superiores às encontradas no estudo. De forma análoga, Ünal et al. (2011) encontraram em folhas de sorgo, conídios de $B$. spicifera com dimensões de $20,0-31,0 \times 7,5-12,5 \mu \mathrm{m}$ e, devido às dimensões encontradas serem muito inferiores, a possibilidade de se considerar $B$. spicifera foi refutada. Além disso, pode-se também desconsiderar B. sorghicola, pois de acordo com Silva et al. (2006) seus conídios possuem $72,5-75,0 \times 10,0-12,5 \mu \mathrm{m}$.

Para a variabilidade das dimensões encontradas, os coeficientes de variação encontrados para comprimento e largura dos conídios ( $8,43 \%$ e $6,37 \%$, respectivamente), se mostraram similares aos encontrados por Carvalho et al. (2014), o qual encontraram para $B$. bicolor em sorgo valores de 8,96\% e 6,95\%.

Em relação à incidência, $A$. alternata se mostrou presente em $41,5 \%$ das sementes. De forma similar, Danelli et al. (2012) encontraram para 45 diferentes cultivares um percentual médio de sementes infectadas com $A$. alternata de $42,8 \%$. Este percentual pode ser ainda maior à exemplo de ensaios em campo realizados por Tanaka et al. (2008), onde encontrou-se percentuais de 83,9 à $87,3 \%$ de sementes infectadas com Alternaria spp. De maneira geral, por muitas vezes serem comercializadas sem tratamento, as sementes de trigo mostram grandes percentuais de incidência de Alternaria spp., sendo a espécie facilmente identificável devido a sua morfologia de conídio e características da colônia (CASA et al., 2012).

Já para B. bicolor, o percentual de incidência foi menor (16,5\%), novamente 
corroborando com os estudos realizados por Tanaka et al. (2008), o qual encontraram um percentual máximo de incidência de Bipolaris spp. de 4,3\% em sementes de trigo. No entanto, apesar de números pouco expressivos, a helmintosporiose é uma das doenças que causam maiores danos à cultura do trigo e atenção deve ser dada devido à alta eficiência de transmissão do patógeno que é de $88 \%$ ao coleóptilo, $68 \%$ ao mesocótilo e $38 \%$ à plúmula e, por isso, seu controle deve ser orientado à semente, visando a redução do inóculo inicial (KOBAYASTI; PIRES, 2011).

$\mathrm{Na}$ análise de regressão para $A$. alternaria, obteve-se como modelo uma equação do segundo grau positiva, ou seja, com tendência a aumentar o percentual de incidência ao longo do tempo. De forma contrária, o modelo obtido por Casa et al. (2012) para A. alternata em sementes de cultivares de trigo ao longo de 180 dias de armazenamento foi linear decrescente. Apesar disso, a incidência até os 45 dias foi semelhante ao presente trabalho, evidenciando a perda de capacidade infecciosa do patógeno nas sementes a longo prazo.

Para B. bicolor, foi possível se obter um modelo de equação do segundo grau negativa. Desta vez, o modelo corroborou com Medina et al. (2009), onde este, ao analisar sementes de triticale ( $X$. triticosecale Wittmack) no decorrer de 12 meses em temperatura ambiente, constatou que houve redução da incidência de $B$. sorokiniana neste período em cada uma de suas análises. Segundo Ferreira et al. (2017), esta redução ocorre devido à perda de viabilidade de micélio e esporos de patógenos no decorrer do tempo que é mitigada pela redução no teor de água e redução das taxas germinativas de estruturas de reprodução do patógenos.

\section{CONCLUSÕES}

Baseando-se em caracteres morfológicos dos conídios analisados, verificou-se a ocorrência de $A$. alternata e $B$. bicolor em sementes de trigo cv. 'BRS 264'.

A espécie $A$. alternata quando comparada à $B$. bicolor ocorre com maior incidência em sementes de trigo 'BRS 264'.

\section{AGRADECIMENTOS}

Os autores agradecem ao apoio oferecido pelo Programa de Bolsa de Incentivo à Pesquisa e Produção Científica (PROBIP) (Edital 31/2018, processo no 201700020009573) e pela bolsa de iniciação científica concedida (PIBIC) pela Universidade Estadual de Goiás (UEG) e também ao Conselho Nacional de Desenvolvimento Científico e Tecnológico (CNPq).

\section{REFERÊNCIAS}

ANGELOTTI, F.; TESSMANN, D.J.; ALVES, T.C.A.; VIDA, J.B.; JACCOUD FILHO, D.S.; HARAKAVA, R. Caracterização morfológica e identificação molecular de isolados de Fusarium graminearum associados à giberela do trigo e triticale no sul do Brasil. Summa Phytopathologica, Botucatu, v.32, n.2, p.177-179, 2006. http://dx.doi.org/10.1590/S0100$\underline{54052006000200013}$

BRASIL. Manual de análise sanitária de sementes. Brasília: Secretaria de Defesa Agropecuária, 2009. 200p.

CARVALHO, D.D.C.; ALVES, E.; BATISTA, T.R.S.; CAMARGOS, R.B.; LOPES, E.A.G.L. Comparison of methodologies for conidia production by Alternaria alternata from citrus. Brazilian Journal of Microbiology, São Paulo, v. 39, n. 4, p. 792798, 2008. http://dx.doi.org/10.1590/S1517$\underline{83822008000400036}$

CARVALHO, D.D.C.; OLIVEIRA, A.M.E.; LAGO, H.M.S.; RODRIGUES, F. Incidência de Bipolaris bicolor em sementes de sorgo granífero no Brasil.

Revista Brasileira de Milho e Sorgo, Sete Lagoas, v.13, n.2, p.240-247, 2014. http://dx.doi.org/10.18512/19806477/rbms.v13n2p240-247

CASA, R.T.; KUHNEM JUNIOR, P.R.; BOGO, A.; BELANI, A.M.M.; BOLZAN, J.M.; OLIVEIRA, F.S.; BLUM, M.M.C. Survey, survival and control of Alternaria alternata in wheat seeds. Revista Brasileira de Sementes, Londrina, v.34, n.3, p.358-365, 2012.

http://dx.doi.org/10.1590/S010131222012000300001

CELANO, M.M.; MACHADO, J.C.; JACCOUD FILHO, D.S.; GUIMARÃES, R.M. Avaliação do potencial de uso da restrição hídrica em teste de sanidade de sementes de trigo visando à detecção de fungos. Revista Brasileira de Sementes, Londrina, v.34, n.4, p.613-618, 2012.
http://dx.doi.org/10.1590/S010131222012000400012 
CORRÊA, B.O.; MOURA, A.B.; DENARDIN, N.D.; SOARES, V.N.; SCHÄFER, J.T.; LUDWIG, J. Influence of bean seed microbiolization on the transmission of Colletotrichum Lindemuthianum (Saac and Magn.). Revista Brasileira de Sementes, Londrina, v.30, p.156-163, 2008. http://dx.doi.org/10.1590/S0101$\underline{31222008000200019}$

DANELLI, A.D.; VIANA, E.; FIALLOS, F.G. Fungos patogênicos detectados em sementes de trigo de ciclo precoce e médio, produzidas em três lugares do Rio Grande do Sul, Brasil. Scientia Agropecuaria, Trujillo, v.3, n.1, p.67-74, 2012.

ĐISALOV, J.; BODROŽA-SOLAROV, M.; BAGI, F.; PETROVIĆ, K.; ĆULAFIĆ, J.; BOČAROV-STANČIĆ, A.; BRLEK, T. First Report of Alternaria tenuissima and Alternaria infectoria on Organic Spelt Wheat in Serbia. Plant Disease, Saint Paul, v.99, n.11, p.1647, 2015. https://doi.org/10.1094/PDIS-1114-1109-PDN

FERREIRA, D.F. Sisvar: a computer statistical analysis system. Ciência e Agrotecnologia, Lavras, v.35, n.6, p.1039-1042, 2011. http://dx.doi.org/10.1590/S1413$\underline{70542011000600001}$

FERREIRA, D.S.; PIRES, L.M.; OLIVEIRA, T.A.S.; PEIXOTO, N.; CARVALHO, D.D.C. Ocorrência de fungos em sementes de feijão "Red Mexican" e seu efeito na germinação. Scientia Agraria Paranensis, Acrelândia, v.16, n.4, p.542-545, $2017 . \quad \quad$ http://dx.doi.org/10.18188/19831471/sap.v16n4p542-545

GARCIA JUNIOR, D.; VECHIATO, M.H.; MENTEN, J.O.M.; LIMA, M.I.P.M. Relação entre a incidência de Fusarium graminearum em sementes, emergência e ocorrência de giberela em plântulas de trigo. Tropical Plant Pathology, Brasília, v.33, n.4, p.302-308, 2008. http://dx.doi.org/10.1590/S1982$\underline{56762008000400007}$

KAHL, S.M.; ULRICH, A.; KIRICHENKO, A.A.; MÜLLER, M.E.H. Phenotypic and phylogenetic segregation of Alternaria infectoria from smallspored Alternaria species isolated from wheat in Germany and Russia. Journal of Applied Microbiology, Oxford, v.119, p.1637-1650, 2015. http://dx.doi.org/10.1111/jam.12951
KHUDHAIR, M.W.; ABOUD, H.M.; DHEYAB, N.S.; SHBAR, A.K.; KHALAF, H.S. The first record of Alternaria triticina the causative agent of alternaria leaf blight in wheat and barley in Iraq. International Journal of Phytopathology, Rawalpindi, v.3, n.3, p.133-138, 2014.

KOBAYASTI, L.; PIRES, A.P. Levantamento de fungos em sementes de trigo. Pesquisa Agropecuária Tropical, Goiânia, v.41, n.4, p.572578, 2011.

http://doi.org/10.5216/pat.v41i4.12388

LIMA, C.S.; SOUZA, P.E.; BOTELHO, A.O. Rust fungi of the Pucciniaceae family on medicinal plants. Fitopatologia Brasileira, Brasília, v.29, n.5, p.499503, 2004. http://dx.doi.org/10.1590/S0100$\underline{41582004000500005}$

MEDINA, P.F.; TANAKA, M.A. de S.; PARISI, J.J.D. Sobrevivência de fungos associados ao potencial fisiológico de sementes de triticale $(X$. triticosecale Wittmack) durante o armazenamento. Revista Brasileira de Sementes, Londrina, v.31, n.4, p.17-26, 2009. http://dx.doi.org/10.1590/S0101$\underline{31222009000400002}$

MISAGHI, I.J.; GROGAN, R.G.; DUNIWAY, J.M.; KIMBLE, K.A. Influence of Environment and culture Media on Spore Morphology of Alternaria alternata. Phytopathology, Saint Paul, v.68, n.1, p.29-34, 1978.

MOREJON, K.R.; MORAES, M.H.D.; BACH, E.E. Identification of Bipolaris bicolor and Bipolaris sorokiniana on wheat seeds (Triticum aestivum L.) in Brazil. Brazilian Journal of Microbiology, São Paulo, v.37, n.3, p.247-250, 2006. http://dx.doi.org/10.1590/S1517$\underline{83822006000300010}$

PERELLÓ, A.; CORDO, C.; SIMON, MR. A new disease of wheat caused by Alternaria triticimaculans in Argentina, Agronomie: Agriculture and Environment, Paris, v.16, p.107112, 1996.

PERELLÓ, A.E.; SISTERNA, M.N. Leaf blight of wheat caused by Alternaria triticina in Argentina. Plant Pathology, Oxford, v.55, p.303, 2006. http://dx.doi.org/10.1111/j.13653059.2005.01264.x 
REIS, E.M. Patologia de Sementes de Cereais de Inverno. São Paulo: CNDA, 1987. 32p.

SILVA, D.D.; CASELA, C.R.; FERREIRA, A.S.; SILVA, V.A.; MARTINS, Z.C.; BORGES, M.H.D.; CASTRO, H.A.; GUIMARAES, F.B. Primeiro relato de Bipolaris sorghicola, agente etiológico da "mancha alvo" em sorgo, no Brasil. Sete Lagoas: ABMS, 2006. Disponível em: https://ainfo.cnptia.embrapa.br/digital/bitstream /item/29675/1/Primeiro-relato.pdf. Acesso em: 20 de fevereiro de 2018.

SOLEIMANI, M.J.; KAZEMI, S. First report of Bipolaris sacchari causing wheat stem-base disease in Iran. Plant Pathology, Oxford, v.55, p.305, 2006. https://doi.org/10.1111/j.13653059.2005.01268.x

TANAKA, M.A. de S.; FREITAS, J.G.; MEDINA, P.F. Incidência de doenças fúngicas e sanidade de sementes de trigo sob diferentes doses de nitrogênio e aplicação de fungicida. Summa Phytopathologica, Botucatu, v.34, n.4, p.313-317, $2008 . \quad$ http://dx.doi.org/10.1590/S0100$\underline{54052008000400002}$

TELLES NETO, F.X.B.; REIS, E.M.; CASA, R.T. Viability of Fusarium graminearum in stored wheat seeds. Summa Phytopathologica, Botucatu, v.33, n.4, p.414-415, 2007.
http://dx.doi.org/10.1590/S0100$\underline{54052007000400017}$

ÜNAL, F.; TURGAY, E. B.; YILDIRIM, A. F.; YÜKSEL, C. First report of leaf blotch on sorghum caused by Bipolaris spicifera in Turkey. Plant Disease, Saint Paul, v. 95, p. 495, 2011. http://dx.doi.org/10.1094/PDIS-01-10-0037

VASCONCELOS, C.V.; SILVA, D.C.; CARVALHO, D.D.C. Ocorrência de Alternaria alternata (Fr.:Fr.) Keissl. em tubérculos de batata, no Brasil. Pesquisa Agropecuária Tropical, Goiânia, v.44, n.2, p.219-222, 2014.

http://dx.doi.org/10.1590/S1983$\underline{40632014000200015}$

XIAO, Z.; BERGERON, H.; LAU, P.C.K. Alternaria alternata as a new fungal enzyme system for the release of phenolic acids from wheat and triticale brans. Antonie van Leeuwenhoek, Montreal, v.101, p.837-844, 2012. http://dx.doi.org/10.1007/s10482-012-9700-8

Recebido para publicação em 05/06/2018 Revisado em 05/01/2019

Aceito em 06/01/2019 